\title{
Investigating Internal Gettering of Iron at Grain Boundaries in Multicrystalline Silicon via Photoluminescence Imaging
}

\author{
AnYao Liu, Daniel Walter, Sieu Pheng Phang, and Daniel Macdonald
}

\begin{abstract}
In this paper, we present measurements and modeling of the reduction in dissolved iron $\mathrm{Fe}$; concentrations near grain boundaries in multicrystalline silicon (mc-Si) wafers. The measurements of the interstitial $\mathrm{Fe}$ concentrations are obtained via photoluminescence images taken before and after iron-boron pair dissociation. A simple diffusion-capture model was developed to characterize the removal of interstitial $\mathrm{Fe}$ by the gettering sites. The model is based on a numerical solution to the 1-D diffusion equation with two fitting parameters: the diffusion length of dissolved $\mathrm{Fe}$ atoms and the effective gettering velocity at the gettering site. By comparing the simulation with a controlled phosphorous gettering process, the model is shown to give good estimation of the diffusion length of $\mathrm{Fe}$ atoms. For as-cut multicrystalline silicon wafers from different parts of the ingot, that is, wafers with different average dissolved $\mathrm{Fe}$ concentrations $\left[\mathrm{Fe}_{i}\right]$, the diffusion lengths of $\mathrm{Fe}$ atoms are found to decrease with decreasing average $\left[\mathrm{Fe}_{i}\right]$. This suggests the presence of relaxation precipitation during the internal gettering of dissolved $\mathrm{Fe}$ by the grain boundaries in $\mathrm{mc}-\mathrm{Si}$ during ingot cooling.
\end{abstract}

Index Terms-Grain boundary (GB), internal gettering, iron, multicrystalline silicon, photoluminescence (PL) imaging.

\section{INTRODUCTION}

I $\mathrm{RON}(\mathrm{Fe})$ is one of the most common and detrimental impurities in multicrystalline silicon (mc-Si) for solar cells, as it introduces strong recombination centers in silicon and thus reduces the carrier lifetime and the subsequent solar cell efficiency [1]-[3]. It originates from the feedstock, the crucible, and crucible lining during the ingot crystallization process [3]. Fe in its dissolved interstitial form is more harmful than precipitates [3], because of its more distributed nature, although this effect is compensated by the fact that dissolved iron can be effectively gettered during cell processing [4]. Structural defects in mc-Si are known to act as internal gettering sites for interstitial $\mathrm{Fe}\left(\mathrm{Fe}_{i}\right)$ to precipitate at during the ingot crystallization process [5]. This paper studies the gettering of $\mathrm{Fe}$ by grain boundaries (GBs) in mc-Si by quantitatively examining

Manuscript received January 16, 2012; revised March 8, 2012 and April 2, 2012; accepted April 4, 2012. Date of publication July 10, 2012; date of current version September 18, 2012. This work was supported in part by the Australian Research Council.

The authors are with the Research School of Engineering, College of Engineering and Computer Science, Australian National University, Canberra, A.C.T. 0200, Australia (e-mail: anyao.liu@anu.edu.au; daniel.walter@ anu.edu.au; pheng.phang@anu.edu.au; daniel.macdonald@anu.edu.au).

Color versions of one or more of the figures in this paper are available online at http://ieeexplore.ieee.org.

Digital Object Identifier 10.1109/JPHOTOV.2012.2195550 the $\mathrm{Fe}_{i}$ distribution near GBs of as-cut mc-Si wafers from different ingot positions, that is, wafers with different average $\mathrm{Fe}_{i}$ concentrations $\left(\left[\mathrm{Fe}_{i}\right]\right)[2],[6]$. The interstitial $\mathrm{Fe}$ images are obtained by photoluminescence (PL) imaging taken before and after dissociation of FeB pairs via strong illumination [7]. A simple diffusion-capture model is used to characterize the diffusion of interstitial $\mathrm{Fe}$ atoms to the gettering site from the PL image line scans. The effects of lateral carrier diffusion during PL imaging and other possible measurement artifacts will also be discussed.

\section{EXPERIMENTAL METHODS}

The mc-Si wafers used in this study were from a commercial p-type boron-doped directionally solidified $\mathrm{mc}-\mathrm{Si}$ ingot, nominally $1.4 \Omega \cdot \mathrm{cm}$ in resistivity, and were $330-\mu \mathrm{m}$ thick. They were from near bottom of the ingot, located at $25.4 \%, 26.7 \%, 28.0 \%$, and $30.8 \%$ from the ingot bottom, with average interstitial $\mathrm{Fe}$ concentrations of $1.3 \times 10^{13}, 1.0 \times 10^{13}, 6.0 \times 10^{12}$, and $2.2 \times 10^{12} \mathrm{~cm}^{-3}$, respectively. To allow sensitive bulk lifetime measurements, which are required for $\left[\mathrm{Fe}_{i}\right]$ imaging, the wafers were surface etched, cleaned, and passivated with silicon nitride by plasma-enhanced chemical vapor deposition (PECVD). The thickness of the deposited silicon nitride is around $60 \mathrm{~nm}$, with an estimated surface recombination velocity of less than $20 \mathrm{~cm} / \mathrm{s}$.

To test the methods and model used, a single-crystalline silicon wafer with an "artificial" GB was fabricated. This was a float-zone (FZ), p-type boron-doped, $0.8 \Omega \cdot \mathrm{cm} 470-\mu \mathrm{m}$ - thick wafer, which was uniformly implanted with $\mathrm{Fe}$ at a relatively low energy of $70 \mathrm{keV}$ with a dose of $5 \times 10^{11} \mathrm{~cm}^{-2}$. The implanted wafer was annealed in oxygen at $1000^{\circ} \mathrm{C}$ for $3 \mathrm{~h}$ to uniformly distribute $\mathrm{Fe}$ throughout the wafer thickness, and to grow a masking oxide of $\sim 0.1-\mu \mathrm{m}$ thick on both sides. The resulting volumetric $\mathrm{Fe}$ concentration is around $1 \times 10^{13} \mathrm{~cm}^{-3}$. Photolithography was used to create a $10-\mu \mathrm{m}$ wide finger through the oxide on one side of the wafer. The wafer then received a 40-min phosphorous diffusion at $800^{\circ} \mathrm{C}$ with a temperature ramp down of $10^{\circ} \mathrm{C} / \mathrm{min}$ to $700^{\circ} \mathrm{C}$, which resulted in a diffusion of around $100 \Omega /$ square in the exposed $10-\mu \mathrm{m}$ line only. This created an "artificial" GB where Fe was gettered. The oxide masks and the phosphorous-doped layer were then etched off, and the wafer was passivated on both sides with silicon nitride by PECVD.

The images of interstitial $\mathrm{Fe}$ concentrations were obtained via PL imaging [8] taken before and after dissociation of FeB 


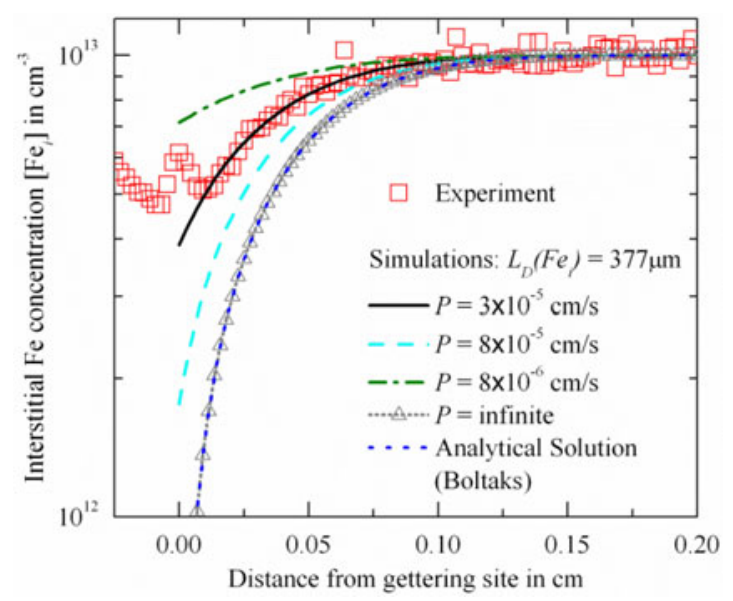

Fig. 1. Using the numerical solution to the time varying 1-D diffusion equation to fit the experimental $\left[\mathrm{Fe}_{i}\right]$ profile near a GB (indicated in Fig. 4) of an ascut mc-Si wafer with an average $\left[\mathrm{Fe}_{i}\right]$ of $1 \times 10^{13} \mathrm{~cm}^{-3}$. The slight increase of $\left[\mathrm{Fe}_{i}\right]$ near the GB is likely due to a measurement artifact, and hence, it is excluded from model fitting. The diffusion length of $\mathrm{Fe}$ atoms, as one of the two fitting parameters, is fixed at $377 \mu \mathrm{m}$ as this gives the best fitting. The effect of the other fitting parameter, that is, the effective gettering velocity at the gettering site $P$, is shown by altering the $P$ values. An analytical solution given by Boltaks [11] is also shown, which is based on the assumption that the gettering site acts as an infinite sink for $\mathrm{Fe}_{i}$.

pairs. The technique for PL imaging of interstitial iron in silicon is detailed in [7]. In this paper, we used an LIS-R1 PL imager from BTImaging with an illumination laser of a wavelength of $808 \mathrm{~nm}$. A zoom lens with a resulting pixel size of $\sim 23 \mu \mathrm{m}$ was used. Low-injection conditions were used for all measurements, with excess carrier densities in the range of $\left(1 \times 10^{13}\right)$ $\left(3 \times 10^{13}\right) \mathrm{cm}^{-3}$. The experimental details for employing the technique in this study can be found in [6]. A point spread function (PSF) [9], [10] was applied to deconvolve image smearing caused by lateral infrared photon scattering within the Si-CCD camera. This was found to be important in this study, as we are quantitatively examining the regions near GBs where rapid changes in PL intensity occur. Line scans of straight GBs were averaged along the length of the GBs to reduce experimental noise.

\section{MODELING}

A simple 1-D diffusion-capture model was developed to determine the diffusion length of $\mathrm{Fe}$ atoms to linear gettering sites from the averaged line scans of $\left[\mathrm{Fe}_{i}\right]$ images. Analytical solutions to the time-dependent 1-D diffusion equation are widely documented [11], [12]. However, the analytical solutions only apply to the case where the gettering site is assumed to be an infinite sink for $\mathrm{Fe}_{i}$, and this was found to create a significant mismatch with experimental data, as shown in Fig. 1. A numerical solution was therefore employed, applying the method outlined in [13], with two fitting parameters - the diffusion length of interstitial $\mathrm{Fe}$ atoms $L_{D}\left(\mathrm{Fe}_{i}\right)$ and the effective gettering velocity at the gettering site $P$ (with units of centimeters per second).

The former parameter physically represents the distance over which Fe has diffused to the identified gettering sites, regardless of the mechanisms that drive such gettering. The diffusion length

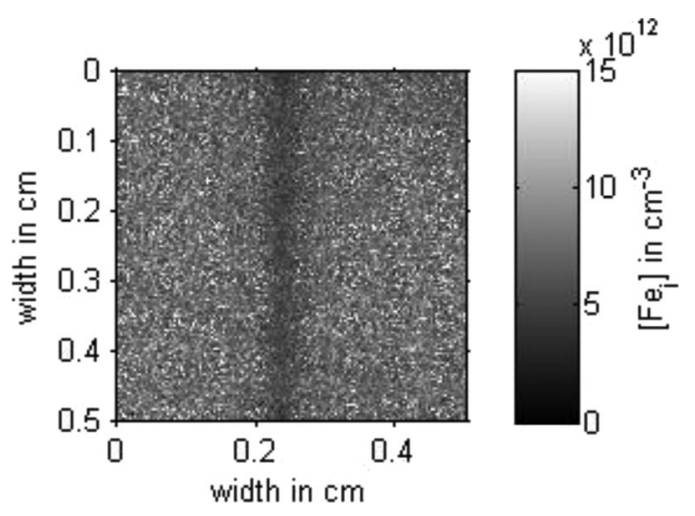

Fig. 2. Interstitial $\mathrm{Fe}$ image of a FZ Si wafer with a uniformly implanted Fe concentration of $1 \times 10^{13} \mathrm{~cm}^{-3}$ and an "artificial grain boundary"-a $10-\mu \mathrm{m}$ - wide line through which a phosphorous diffusion was performed for Fe gettering.

of Fe atoms, which is also termed as the Fe diffusion length in the following text, is related to the diffusivity of $\mathrm{Fe} D$ and time duration via

$$
L_{D}\left(F e_{i}\right)=\sqrt{\int_{t_{o}}^{t_{f}} D d t}
$$

where $t_{o}$ and $t_{f}$ denote the start and end time of the Fe diffusion process.

The effective gettering velocity at the gettering site is directly analogous to the surface recombination velocity for the recombination of minority carriers at wafer surfaces. The gettering velocity $P$ can be considered a physical property of the gettering sites, and for the case of segregation gettering, it is defined in terms of the surface gettering rate $U_{S}$, the interstitial iron concentration in the vicinity of the gettering site (GS) $\left[F_{i}\right]_{\mathrm{GS}}$, via $U_{s}=P \times\left[F e_{i}\right]_{\mathrm{GS}}$; for the case of gettering via precipitation of supersaturated $\mathrm{Fe}_{i}$, the equation becomes $U_{s}=P \times\left(\left[F e_{i}\right]_{\mathrm{GS}}-S\right)$, where $S$ is the solubility of $F e_{i}$ in silicon. This can be simplified to $U_{s}=P \times\left[F e_{i}\right]_{\text {GS }}$, because first the onset of precipitation requires high levels of supersaturation as shown in [14]-[16] as well as demonstrated in latter section of this paper; and second, because we are examining wafers with practical ingot cooling rates.

As shown in Figs. 1, 3, and 5, the simulation matches well with experimental data, indicating that this simple model can be used to characterize the diffusion and the capture of Fe to the gettering sites. The sensitivity of the fit to the effective gettering velocity is illustrated in Fig. 1 for a fixed Fe diffusion length. When the gettering velocity $P$ was set to an infinitely large value, simulating the case where the gettering site acts as an infinite sink, the results from the numerical solution matches identically with the analytical solution from Boltaks [11], as can be seen in Fig. 1.

\section{RESUlts AND Discussion}

\section{A. Technique and Model Confirmation}

Fig. 2 shows the $\left[\mathrm{Fe}_{i}\right]$ image of the FZ wafer with the "artificial GB"- - a thin line through which a phosphorous diffusion 


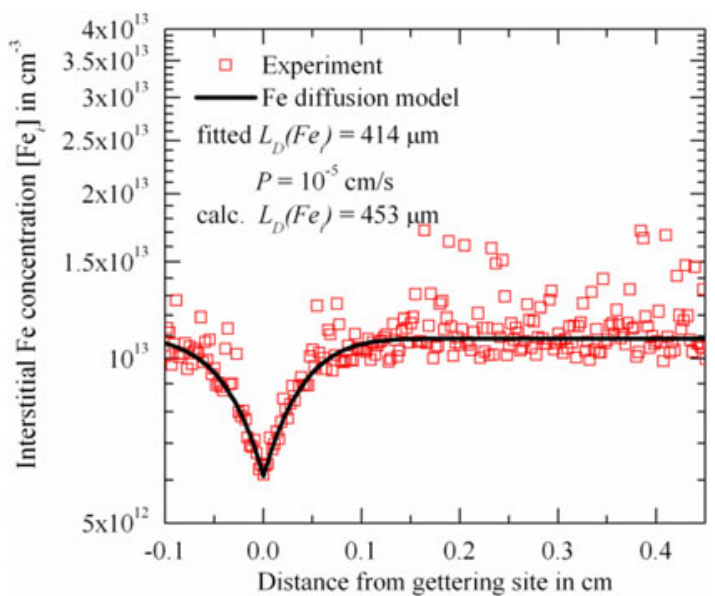

Fig. 3. Interstitial Fe profile of the artificial GB created by uniform Fe implanted FZ Si wafer with a thin line for phosphorous gettering. The corresponding $\left[\mathrm{Fe}_{i}\right]$ image is shown in Fig. 2. The smooth line represents the Fe diffusion simulation where the diffusion length of Fe atoms $L_{D}\left(F_{i}\right)$ is $414 \mu \mathrm{m}$ and the where gettering velocity at the gettering site is $10^{-5} \mathrm{~cm} / \mathrm{s}$. The diffusion length of Fe atoms calculated from the known gettering temperature and time is $453 \mu \mathrm{m}$, therefore verifying the model as a useful tool to estimate $L_{D}\left(\mathrm{Fe}_{i}\right)$.

was performed to getter $\mathrm{Fe}$ in a uniformly implanted single crystalline wafer. Based on the known diffusivity of interstitial $\mathrm{Fe}$ in silicon [17], the diffusion length of $\mathrm{Fe}$ atoms during the controlled gettering process was calculated to be $453 \mu \mathrm{m}$. The $L_{D}\left(F_{i}\right)$ found by fitting the model to the $\left[\mathrm{Fe}_{i}\right]$ image line scans gives a value of $414 \mu \mathrm{m}$ (see Fig. 3). This close agreement, therefore, verifies the simple Fe diffusion-capture model used to estimate $L_{D}\left(F e_{i}\right)$ from line scans of PL $\left[\mathrm{Fe}_{i}\right]$ images near a gettering site.

It is interesting to note from Fig. 3 that a $10-\mu \mathrm{m}$ - wide line of phosphorous gettering is much less effective than a full area gettering layer. Similar phosphorous diffusion conditions across the whole surface of a silicon wafer reveal reductions in $\left[\mathrm{Fe}_{i}\right]$ by about two orders of magnitude [4], [6], whereas here we only observe a reduction by a factor of $\sim 2$, due to the continuous diffusion of $\mathrm{Fe}$ from the surrounding regions. This could have implications for selective emitter structures whose gettering capability may be limited, unless an extra gettering step is included or a longer diffusion time is used.

\section{B. Gettering of Fe to Grain Boundaries in $\mathrm{mc}-\mathrm{Si}$}

Internal gettering of interstitial $\mathrm{Fe}$ to the GBs in mc-Si is obvious from the $\left[\mathrm{Fe}_{i}\right]$ image of an as-cut mc-Si wafer (see Fig. 4). Note that the degree of gettering at GBs varies at different GBs, as has been observed previously [18]-[20]. In our simple diffusion-capture model, these differences are reflected by changes to the effective gettering velocity.

There are two types of mc-Si internal gettering mechanismsrelaxation and segregation [21], [22]. $\mathrm{Fe}_{i}$ only precipitates heterogeneously at extrinsic defects [23], and for $\mathrm{mc}-\mathrm{Si}$, these are mainly the structural defects [24]. For the relaxation mechanism, in principle, $\mathrm{Fe}_{i}$ in the vicinity of the gettering sites (i.e., structural defects) starts to precipitate some point after it reaches its solubility limit, as the structural defects provide lower nucle-

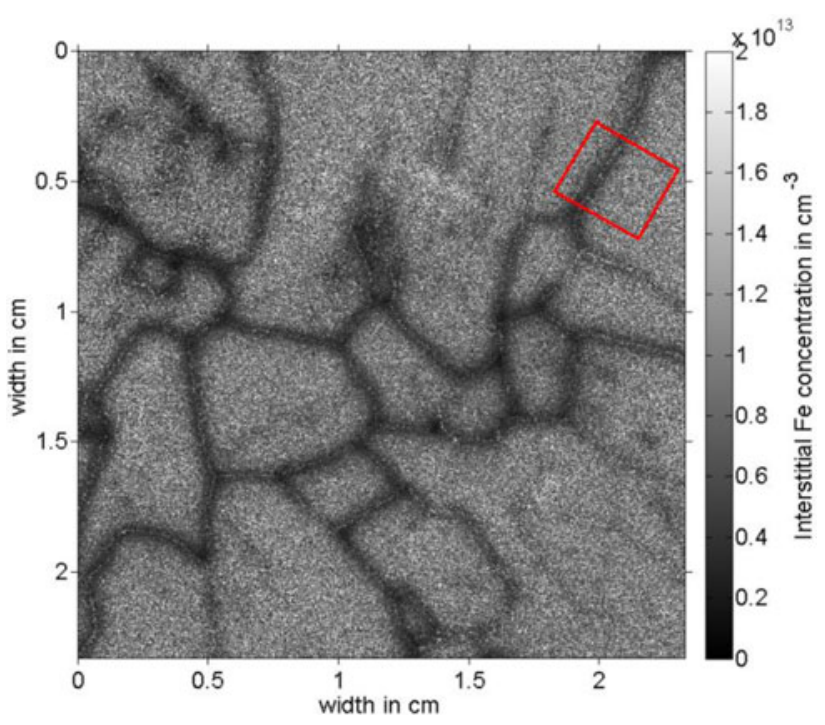

Fig. 4. Interstitial $\mathrm{Fe}$ image of an as-cut mc-Si wafer, with an average $\left[\mathrm{Fe}_{i}\right]$ of $1 \times 10^{13} \mathrm{~cm}^{-3}$. The red rectangle indicates the straight GB whose line scans were averaged to produce a less noisy $\mathrm{Fe}_{i}$ profile, as shown in Figs. 1 and 5.

ation barriers for the formation of precipitates. Such a decline in $\left[\mathrm{Fe}_{i}\right]$ drives $\mathrm{Fe}_{i}$ within the perfect crystals to diffuse toward structural defects, until its diffusivity becomes too low as the ingot cools down. The remaining $\mathrm{Fe}_{i}$ stays supersaturated within the crystals. The $\left[\mathrm{Fe}_{i}\right]$ profiles across a number of millimeterto-centimeter large grains within the four mc-Si wafers show that the $\left[\mathrm{Fe}_{i}\right]$ profile far from the denuded zone is quite flat (an example is shown in Fig. 1). This indicates little or uniform precipitation sites within such grains. The uniform $\left[\mathrm{Fe}_{i}\right]$ away from the denuded zone in the relatively large grains is used as the input of initial $\mathrm{Fe}_{i}$ concentration in modeling the subsequent diffusion of $\mathrm{Fe}_{i}$ to the GB. Relaxation gettering is driven by the decreasing solubility limit during ingot cooling. Segregation gettering, on the other hand, is an equilibrium process driven by higher solubilities of $\mathrm{Fe}_{i}$ at the structural defects of silicon than within the perfect crystals [21], [22].

Fig. 5 shows the comparison of the normalized $\left[\mathrm{Fe}_{i}\right]$ profiles of several mc-Si wafers with different average $\left[\mathrm{Fe}_{i}\right]$. The waferaveraged $\left[\mathrm{Fe}_{i}\right]$ roughly equates to the concentrations of $\mathrm{Fe}_{i}$ within the grains away from the denuded zones near GBs. Note that the comparison was made on the same GB identified on the neighboring wafers. The diffusion length of $\mathrm{Fe}$ atoms is shown to decrease with decreasing average $\left[\mathrm{Fe}_{i}\right]$, suggesting the presence of relaxation gettering by the GBs. This is because during the mc-Si ingot cooling, regions of lower $\left[\mathrm{Fe}_{i}\right]$ reach the solubility limit at a later stage, meaning that $\mathrm{Fe}_{i}$ has less time to diffuse to GBs and thus has a shorter diffusion length. The effective gettering velocity at the GB, $P$, is found to also decrease with decreasing average $\left[\mathrm{Fe}_{i}\right]$. This is consistent with Ham's model [25], as the wafers with lower $\left[\mathrm{Fe}_{i}\right]$ have lower average $\mathrm{Fe}_{i}$ diffusivities because precipitation starts at lower temperatures, and smaller radius of precipitates as a result of shorter precipitation time.

The total Fe concentrations of the wafers from the same ingot have been measured previously by neutron activation analysis 


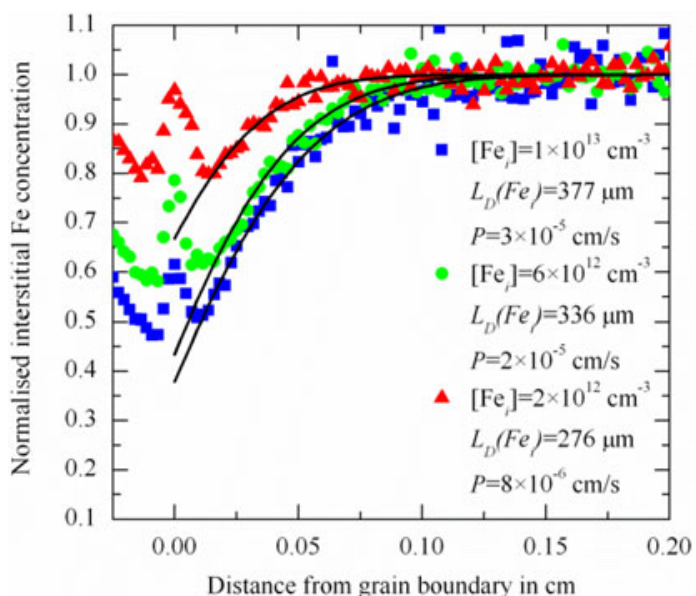

Fig. 5. Normalized $\mathrm{Fe}_{i}$ profiles near GBs taken from averaged line scans of the same straight GB (as indicated in Fig. 4) identified on the neighboring wafers with different wafer-average interstitial Fe concentrations. Smooth lines represent model fitting.

in [2]. These results [2] suggest that that the wafers examined in this paper have total $\mathrm{Fe}$ concentrations in the range of $(2-3) \times 10^{14} \mathrm{~cm}^{-3}$, which are 1-2 orders of magnitude higher than the measured interstitial Fe concentrations. The vast majority of $\mathrm{Fe}$ is therefore in the precipitated form. The narrow denuded zones of the $\left[\mathrm{Fe}_{i}\right]$ profiles (see Fig. 5) indicate that the gettering capability of the GBs is quite limited. The majority of Fe precipitates are therefore likely from the following sources: the inclusion of large Fe-rich foreign particles which were not dissolved during the entire crystallization process [3]; dissolved $\mathrm{Fe}$ atoms segregating to structural defects at high temperatures [21], [22]; and the internal gettering of $\mathrm{Fe}_{i}$ by other crystal defects and nucleation sites within the grains [24]. Other paths and mechanisms may also exist.

For the scenario where relaxation gettering is the dominating mechanism that results in the estimated Fe diffusion length from the measured $\left[\mathrm{Fe}_{i}\right]$ images, $t_{o}$ in (1) denotes the time when the local $\left[\mathrm{Fe}_{i}\right]$ reaches a multiple of its solubility limit, that is, $t$ at which $\left[F e_{i}\right]_{\text {init }}=S(T(t)) \times k$, where $S$ is Fe solubility [26], $T(t)$ is the ingot cooling rate, and $k$ is the supersaturation ratio required for the onset of precipitation [14]-[16]; $t_{f}$ is the end of the cooling time. The relation of Fe diffusivity with temperature $D(T)$ used in (1) is from [17].

The actual ingot cooling profile $T(t)$ is not known for the ingot studied here. However, from the fitted $L_{D}\left(F e_{i}\right)$ values, the cooling rate can be estimated from (1), assuming $T(t)$ has an exponential decay below $1000^{\circ} \mathrm{C}$. For the $L_{D}\left(F e_{i}\right)$ of the wafer with an average $\left[\mathrm{Fe}_{i}\right]$ of $1 \times 10^{13} \mathrm{~cm}^{-3}$ (see Fig. 5) and an assumed supersaturation ratio $k$ of one, this gives a 2-h decay time constant for an exponential $T(t)$. The $L_{D}\left(F e_{i}\right)$ trend calculated from this time constant matches well with the rest of the experimental results, as shown in Fig. 6.

However, a 2-h time constant seems too short for an industrial process. The cooling profiles of directionally solidified mc-Si ingots vary significantly for different ingot sizes as well as from different manufacturers. For this study, we used the cooling rates of the following four mc-Si ingots which are $12 \mathrm{~kg}$ [27], $80 \mathrm{~kg}$

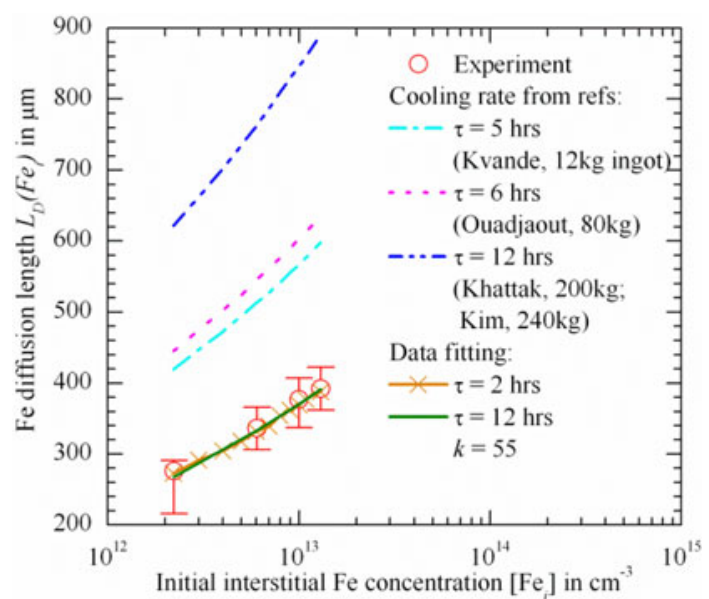

Fig. 6. Diffusion lengths of Fe atoms of the four as-cut mc-Si wafers with respect to the wafer-average interstitial Fe concentrations, in comparison with those calculated from the cooling rates of different sized ingots from [27]-[30]. The graph also includes the $L_{D}\left(F e_{i}\right)$ trend calculated from the cooling rate estimated from the experimental $L_{D}\left(\mathrm{Fe}_{i}\right)$ of the wafer with an average $\left[\mathrm{Fe}_{i}\right]$ of $1 \times 10^{13} \mathrm{~cm}^{-3}$. To simulate the effect of supersaturation on the onset of precipitation, the $L_{D}\left(F_{i}\right)$ trend is also calculated from a supersaturation ratio $k$ of 55 and an exponential temperature decay time constant of $12 \mathrm{~h}$ for temperatures below $1000^{\circ} \mathrm{C}$.

[28], $200 \mathrm{~kg}$ [29], and $240 \mathrm{~kg}$ [30], with exponential temperature decay time constants of 5, 6, and $12 \mathrm{~h}$ (for both $200 \mathrm{~kg}$ and $240 \mathrm{~kg}$ ingots), respectively, for temperatures below $1000^{\circ} \mathrm{C}$. The Fe diffusion lengths calculated from these cooling rates with an assumed supersaturation ratio $k$ of one are included in Fig. 6, all of which show a similar trend to that of the experimental data, but with higher magnitudes.

The mc-Si wafers studied in this paper are from an industrially grown ingot, and hence we assume that its cooling rate is similar to that of the $200 \mathrm{~kg}$ [29] and $240 \mathrm{~kg}$ [30] ingots. For a supersaturation ratio $k$ of 55 , the trend of the Fe diffusion lengths calculated from the cooling decay constant of $12 \mathrm{~h}$ agrees well with the experimental results, as shown in Fig. 6. In addition, a supersaturation ratio of 55 is in the range of 11160 calculated from the precipitation onset temperatures given in [14]-[16]. The apparent supersaturation ratio is likely to relate to a nucleation-limited precipitation process [14], [15]. It might also be caused by higher solubilities of Fe in the strained and dislocated regions very close to the GBs, compared with the relatively unstrained single crystalline silicon within the grains [21], [22]. This speculation would imply that during cooling a segregation mechanism is present as well, along with relaxation precipitation.

\section{Measurement Artifacts}

As the minority carrier diffusion lengths $L_{D}\left(e^{-}\right)$of the tested wafers are around two to six times larger than the imaging pixel size of $23 \mu \mathrm{m}$, lateral carrier diffusion is expected to cause some image smearing. In the case of lower lifetime samples, such as the "artificial GB" wafer whose $L_{D}\left(e^{-}\right)$is about two to three times larger than the image pixel size, carrier smearing does not have a significant impact on the estimation of the diffusion length of Fe atoms $L_{D}\left(F e_{i}\right)$, as demonstrated by comparing 


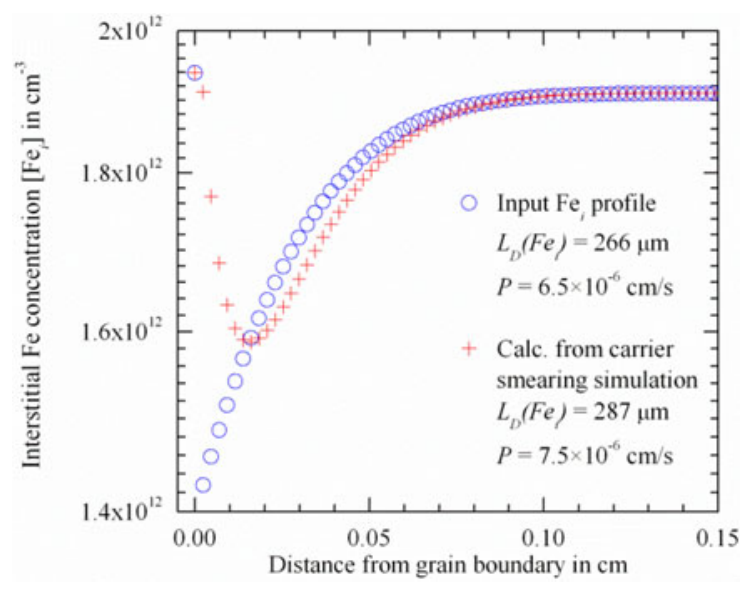

Fig. 7. Simulation of the effect of minority carrier diffusion smearing on the resulting interstitial $\mathrm{Fe}$ profile near a $\mathrm{GB}$ for a $\mathrm{mc}-\mathrm{Si}$ wafer with minority carrier diffusion lengths of $135 \mu \mathrm{m}$ (lifetime $6.5 \mu \mathrm{s}$ ) in the FeB paired state and $100 \mu \mathrm{m}$ (lifetime $3.5 \mu \mathrm{s})$ in the $\mathrm{Fe}_{i}$ state, at injection levels of $(2-3) \times 10^{13} \mathrm{~cm}^{3}$.

the model fitted $L_{D}\left(F_{i}\right)$ with that calculated from the known diffusion conditions (see Fig. 3). In the case of larger $L_{D}\left(e^{-}\right)$ wafers, the effect of carrier diffusion on the resulting Fe profiles was simulated, by solving the 1-D diffusion equation for photogenerated carriers at steady state, allowing for diffusion and recombination. A fitted Fe profile and uniform $\tau_{\text {other }}$ estimated from experimental data were taken as inputs to calculate the effective lifetime profiles near GBs in both $\mathrm{FeB}$ and $\mathrm{Fe}_{i}$ states, based on the Shockley-Read-Hall model [31]-[33], with the same values of energy levels and capture cross sections for FeB and $\mathrm{Fe}_{i}$ as were used in [7]. For a more realistic simulation, experimental data of the lifetimes in the vicinity of the GB were used. The effective minority carrier lifetimes away from the denuded zone are $6.5 \mu \mathrm{s}\left(L_{D}\left(e^{-}\right) \sim 135 \mu \mathrm{m}\right)$ in the FeB state and $3.5 \mu \mathrm{s}\left(L_{D}\left(e^{-}\right) \sim 100 \mu \mathrm{m}\right)$ in the $\mathrm{Fe}_{i}$ state, at injection levels of $(2-3) \times 10^{13} \mathrm{~cm}^{3}$. This represents the tested wafer with the highest lifetime, that is, the worst smearing case. Carrier diffusion simulation was then applied to the corresponding excess carrier density profiles. The resulting diffused excess carrier profiles were used to generate a new $\left[\mathrm{Fe}_{i}\right]$ profile, which was compared with the original input $\left[\mathrm{Fe}_{i}\right]$ profile, as shown in Fig. 7. For the wafer with the worst carrier smearing examined in this study, this is shown to cause only slight overestimation of $L_{D}\left(F e_{i}\right)$ and $P$. Note, however, that the effect of such carrier smearing could become more significant for higher lifetime samples.

The $\mathrm{Fe}_{i}$ images of mc-Si consistently show a slight increase of $\left[\mathrm{Fe}_{i}\right]$ very close to the GBs (see Figs. 1, 4, and 5), an effect also observed by Schubert et al. [34]. The "artificial GB," however, has no such effect (see Figs. 2 and 3). The carrier smearing simulation where lifetimes in the vicinity of the GBs were set to be experimental values also demonstrated such increase (see Fig. 7). This increase could be due to a measurement artifact in the vicinity of the GBs, which are very strong recombination sites. A possible cause is the lateral scattering of PL within the silicon wafer. This is not dealt with by the application of the PSF, which only corrects for the lateral scattering within the Si camera. Lateral scattering of PL causes some PL from regions near GBs to be emitted at the GBs, and because the $\left[\mathrm{Fe}_{i}\right]$ image is obtained by the two lifetime images taken before and after disassociation of $\mathrm{FeB}$ pairs, the difference in excess carrier densities leads to uneven scattering contributions to regions very close to the GBs. In a similar way, lateral carrier diffusion may also be one of the causes, as simulated in [34]. However, note that the extent of this hump is small compared with the denuded zone width, and therefore it does not significantly affect our model fitting.

\section{CONCLUSION}

This paper has demonstrated the use of a simple Fe diffusioncapture model to characterize the reduction in dissolved $\mathrm{Fe}$ concentrations by the gettering sites from $\left[\mathrm{Fe}_{i}\right]$ images obtained via PL imaging. The model is based on a numerical solution to the time-dependent 1-D diffusion equation with two fitting parameters- the diffusion length of $\mathrm{Fe}$ atoms and the effective gettering velocity at the gettering site. By comparing the modelfitted diffusion length of $\mathrm{Fe}$ atoms to that calculated from a controlled phosphorous gettering process, the model is shown to give a good estimation of the diffusion length of $\mathrm{Fe}$ atoms. To study the internal gettering of $\mathrm{Fe}$ by GBs in as-cut $\mathrm{mc}-\mathrm{Si}$, $\left[\mathrm{Fe}_{i}\right]$ profiles near GBs of wafers from different parts of an ingot, that is, wafers with different average interstitial $\mathrm{Fe}$ concentrations, were compared. The diffusion lengths of Fe atoms of as-cut $\mathrm{mc}-\mathrm{Si}$ wafers are found to decrease with decreasing average $\left[\mathrm{Fe}_{i}\right]$, suggesting the presence of relaxation gettering during ingot cooling. The process of Fe gettering by GBs during ingot cooling that is reflected by the measured denuded zones near GBs, however, only accounts for a small fraction of the total $\mathrm{Fe}$ precipitates in $\mathrm{mc}-\mathrm{Si}$. The effect of lateral carrier diffusion smearing on the estimation of the diffusion length of Fe atoms was examined for wafers with a minority carrier diffusion length six times larger than the imaging pixel size, which represents the worst smearing examined in this study, and it was found to result in only slight overestimation of the diffusion length of $\mathrm{Fe}$ atoms and the effective gettering velocity. An apparent increase in $\left[\mathrm{Fe}_{i}\right]$ profile very close to the GB was observed, which may be due to measurement artifacts at regions of extremely low lifetime.

\section{ACKNOWLEDGMENT}

The authors would like to thank Dr. T. Trupke for helping with the development of the point spread function. They would also like to thank C. Samundsett and Dr. A. Shalav for assistance with sample preparation, as well as S. Baker-Finch and Prof. A. Cuevas for insightful discussions.

\section{REFERENCES}

[1] A. A. Istratov, H. Hieslmair, and E. R. Weber, "Iron contamination in silicon technology," Appl. Phys. A, vol. 70, pp. 489-534, 2000.

[2] D. Macdonald, A. Cuevas, A. Kinomura, Y. Nakano, and L. J. Geerligs, "Transition-metal profiles in a multicrystalline silicon ingot," J. Appl. Phys., vol. 97, 033523, 2005.

[3] T. Buonassisi, A. Istratov, M. Heuer, M. Marcus, R. Jonczyk, J. Isenberg, B. Lai, Z. Cai, S. Heald, W. Warta, R. Schindler, G. Willeke, and E. Weber, "Synchrotron-based investigations of the nature and impact of iron 
contamination in multicrystalline silicon solar cells," J. Appl. Phys., vol. 97, 074901, 2005

[4] S. P. Phang and D. Macdonald, "Direct comparison of boron, phosphorus, and aluminum gettering of iron in crystalline silicon," J. Appl. Phys., vol. 109, 073521, 2011.

[5] T. Buonassisi, A. A. Istratov, M. D. Pickett, M. Heuer, J. P. Kalejs, G. Hahn, M. A. Marcus, B. Lai, Z. Cai, S. M. Heald, T. F. Ciszek, R. F. Clark, D. W. Cunningham, A. M. Gabor, R. Jonczyk, S. Narayanan, E. Sauar, and E. R. Weber, "Chemical natures and distributions of metal impurities in multicrystalline silicon materials," Prog. Photovolt.: Res. Appl., vol. 14, pp. 513-531, 2006.

[6] A. Y. Liu, Y. C. Fan, and D. Macdonald, "Interstitial iron concentrations across multicrystalline silicon wafers via photoluminescence imaging," Prog. Photovolt.: Res. Appl., vol. 19, pp. 649-657, 2011.

[7] D. Macdonald, J. Tan, and T. Trupke, "Imaging interstitial iron concentrations in boron-doped crystalline silicon using photoluminescence," $J$. Appl. Phys., vol. 103, 073710, 2008.

[8] T. Trupke, R. A. Bardos, M. C. Schubert, and W. Warta, "Photoluminescence imaging of silicon wafers," Appl. Phys. Lett., vol. 89, 044107 , 2006.

[9] D. Walter, A. Liu, E. Franklin, D. Macdonald, B. Mitchell, and T. Trupke, "Contrast enhancement of luminsecence images via point-spread deconvolution," in Proc. 38th IEEE Photovoltaic Spec. Conf., Austin, TX, Jun. 2012, to be published.

[10] B. Mitchell, J. Greulich, D. Walter, D. Macdonald, J. W. Weber, and T. Trupke, "On the methodology of photoluminescence spectral intensity ratio imaging of silicon bricks: advances and limitations," J. Appl. Phys., to be published.

[11] B. I. Boltaks, Diffusion in Semiconductors. London, U.K.: Infosearch, 1963, p. 109.

[12] J. Crank, The Mathematics of Diffusion, 2nd ed. London, U.K.: Oxford Univ. Press, 1975, p. 47.

[13] H. Hieslmair, S. Balasubramanian, A. A. Istratov, and E. R. Weber, "Gettering simulator: Physical basis and algorithm," Semicond. Sci. Technol., vol. 16, pp. 567-574, 2001.

[14] A. Haarahiltunen, H. Väinölä, O. Anttila, M. Yli-Koski, and J. Sinkkonen, "Experimental and theoretical study of heterogeneous iron precipitation in silicon," J. Appl. Phys., vol. 101, 043507, 2007.

[15] A. Haarahiltunen, H. Savin, M. Yli-Koski, H. Talvitie, M. Asghar, and J. Sinkkonen, "As-grown iron precipitates and gettering in multicrystalline silicon," Mat. Sci. Eng. B, vol. 159/160, pp. 248-252, 2009.

[16] D. A. Ramappa and W. B. Henley, "Stability of iron-silicide precipitates in silicon," J. Electrochem. Soc., vol. 144, pp. 4353-4356, 1997.

[17] A. Istratov, H. Hieslmair, and E. Weber, "Iron and its complexes in silicon," Appl. Phys. A, vol. 69, pp. 13-44, 1999.

[18] J. Chen, T. Sekiguchi, and Y. D., "Electron-beam-induced current study of grain boundaries in multicrystalline Si," Phys. Stat. Sol. C, vol. 4, pp. 2908-2917, 2007.

[19] J. Chen and T. Sekiguchi, "Carrier recombination activity and structural properties of small-angle grain boundaries in multicrystalline silicon," Jpn. J. Appl. Phys., vol. 46, pp. 6489-6497, 2007.

[20] T. Buonassisi, A. A. Istratov, M. D. Pickett, M. A. Marcus, T. F. Ciszek, and E. R. Weber, "Metal precipitation at grain boundaries in silicon: Dependence on grain boundary character and dislocation decoration," Appl. Phys. Lett., vol. 89, 042102, 2006.

[21] A. A. Istratov, W. Huber, and E. R. Weber, "Experimental evidence for the presence of segregation and relaxation gettering of iron in polycrystalline silicon layers on silicon," Appl. Phys. Lett., vol. 85, pp. 4472-4474, 2004.

[22] A. A. Istratov, T. Buonassisi, W. Huber, and E. Weber, "Evidence for segregation of iron at grain boundaries in polycrystalline," in Proc. 14th Workshop Cryst. Silicon Sol. Cells Modules: Mater. Process., 2004, pp. 230233.

[23] K. Graff, "Transition metals in silicon and their gettering behaviour," Mat. Sci. Eng. B, vol. 4, pp. 63-69, 1989.

[24] J. Schön, H. Habenicht, M. C. Schubert, and W. Warta, "Understanding the distribution of iron in multicrystalline silicon after emitter formation: Theoretical model and experiments," J. Appl. Phys., vol. 109, 063717, 2011.

[25] F. S. Ham, "Theory of diffusion-limited precipitation," J. Phys. Chem. Solids, vol. 6, pp. 335-351, 1958.

[26] J. D. Murphy and R. J. Falster, "Contamination of silicon by iron at temperatures below $800^{\circ}$ C," Phys. Status Solidi RRL, vol. 5, pp. 370$372,2011$.
[27] R. Kvande, L. J. Geerligs, G. Coletti, L. Arnberg, M. Di Sabatino, E. J. Øvrelid, and C. C. Swanson, "Distribution of iron in multicrystalline silicon ingots," J. Appl. Phys., vol. 104, 064905, 2008.

[28] D. Ouadjaout, Y. Gritli, L. Zair, and M. Boumaour, "Growth by the heat exchanger method and characterization of multi-crystalline silicon ingots for PV," Rev. Energ. Ren., vol. 8, pp. 49-54, 2005.

[29] C. P. Khattak and F. Schmid, "Growth and characterization of $200 \mathrm{~kg}$ multicrystalline silicon ingots by HEM," in Proc. 26th IEEE Photovoltaic Spec. Conf., Anaheim, CA, Sep./Oct. 1997, pp. 111-114.

[30] J. M. Kim and Y. K. Kim, "Growth and characterization of $240 \mathrm{~kg} \mathrm{mul}-$ ticrystalline silicon ingot grown by directional solidification," Sol. Energ. Mat. Sol. C., vol. 81, pp. 217-224, 2004.

[31] W. Shockley and W. T. Read, "Statistics of the recombinations of holes and electrons," Phys. Rev., vol. 87, pp. 835-842, 1952.

[32] R. N. Hall, "Electron-hole recombination in germanium," Phys. Rev., vol. 87 , pp. $387-387,1952$

[33] D. Macdonald and A. Cuevas, "Validity of simplified Shockley-ReadHall statistics for modeling carrier lifetimes in crystalline silicon," Phys. Rev. B, vol. 67, 075203, 2003.

[34] M. C. Schubert, H. Habenicht, and W. Warta, "Imaging of metastable defects in silicon," IEEE J. Photovolt., vol. 1, no. 2, pp. 168-173, Oct. 2011.

AnYao Liu received the B.E. (Hons.) degree in sustainable energy systems from the Australian National University, Canberra, A.C.T., Australia, in 2010, where she is currently working toward the Ph.D. degree in photovoltaics engineering.

Daniel Walter is currently working toward the Ph.D. degree with the Centre for Sustainable Energy Systems, Australian National University, Canberra, A.C.T., Australia.

$\mathrm{He}$ is researching laser processing techniques for silicon solar cell fabrication and the application of photoluminescence imaging to laser processing.

Sieu Pheng Phang received the B.E. (Hons.) degree from the Australian National University, Canberra, A.C.T., Australia, in 2008, where he is currently working toward the $\mathrm{Ph} . \mathrm{D}$. degree in photovoltaics engineering.

Daniel Macdonald received the Bachelor of Physical Science degree from La Trobe University, Melbourne, Australia, in 1993 and the Ph.D. degree in engineering from the Australian National University (ANU), Canberra, A.C.T., Australia, in 2001.

Since 2001, he has been a Postdoctoral Fellow with ANU. He was a Research Scientist with the Energy Research Centre of the Netherlands in 2003. He is currently an Australian Research Council Queen Elizabeth II Fellow with the Research School of Engineering, ANU, where his research is focused on defects and impurities in crystalline silicon solar cells. 